\title{
Crystal Structure and Charge Distribution of Pyrazine: Effects of Extinction, Thermal Diffuse Scattering and Series Termination*
}

\author{
By G. DE With, S. Harkema AND D. Feil \\ Chemical Physics Laboratory, Twente University of Technology, P.O. Box 217, Enschede, The Netherlands
}

(Received 26 April 1976; accepted 14 June 1976)

\begin{abstract}
The crystal structure and electronic charge distribution of pyrazine (1,4-diazabenzene) has been determined at $184 \mathrm{~K}$ by X-ray methods. The structural results of Wheatley [Acta Cryst. (1957), 10, 182-187] have been confirmed. A clear indication of bonding effects is obtained. Neither positional and thermal parameters nor difference-Fourier maps are affected by extinction. The effect of thermal diffuse scattering (TDS) on positional parameters is also negligible. However, after correction for TDS, thermal parameters increase significantly. The difference-Fourier map is influenced by TDS as well as the inclusion of high-order Fourier terms.
\end{abstract}

\section{Introduction}

Although the crystal structure of pyrazine $\left(\mathrm{C}_{4} \mathrm{H}_{4} \mathrm{~N}_{2}\right)$ has been determined quite accurately (Wheatley, 1957) as judged by the $R$ index $(R=8.3 \%)$, in the resulting difference-Fourier map no indication of bonding features was found. At present, however, it is possible to obtain X-ray results which do show reliable bonding features (see for example, Stevens \& Hope, 1975). A determination of the charge distribution was therefore carried out by means of X-ray methods.

\section{Experimental}

From commercially available pyrazine (Merck), crystals were selected. Most of them were twinned. Crystals of about $1.0 \mathrm{~mm}$ linear dimension, which were given some time to vaporize to the right size $(\simeq 0.5 \mathrm{~mm})$, proved to be the best. Because pyrazine crystals are highly deformable special care in handling them is necessary. The crystals were fixed on top of a thin capillary with Araldite. This capillary was inserted in a somewhat wider one, which was sealed to prevent further evaporation of the crystal. An approximately spherical crystal (radius $0.25 \mathrm{~mm}$ ) was used for the measurements.

The crystal was mounted on a Philips PW1100 computer-controlled automatic four-circle diffractometer (Mo $K \alpha$ radiation, $\lambda=0.7107 \AA$, graphite monochromator, scintillation counter, pulse-height discriminator). Measurements were performed at $184 \mathrm{~K}$. This temperature was established by means of a Leyboldt-Heraeus NCD 1 cooling device. The temperature proved to be stable within $1 \mathrm{~K}$.

* Part of this research has been carried out under the auspices of the Foundation for Fundamental Research on Matter by Electrons and X-rays (FOMRE) and with aid from the Netherlands Organization for Advancement of Pure Research (ZWO).
Reflexions were measured through the whole hemisphere up to $s=\sin \theta / \lambda=1 \cdot 0 \AA^{-1}\left(\theta=45^{\circ}\right)$. The $\omega / 2 \theta$ scanning technique at a rate of $0.1^{\circ} \mathrm{s}^{-1}$ and a scan width of $(2 \cdot 5+0.5 \tan \theta)^{\circ}$ was used throughout. The detector aperture was chosen as $4.0^{\circ}$ horizontally and $1.5^{\circ}$ vertically.

Cell constants (Table 1) were determined by a leastsquares procedure on the angular coordinates of 25 accurately centred reflexions. The systematic absences ( $h 0 l$ with $h+k$ odd and $h k 0$ with $h+k$ odd) as observed by Wheatley (1957) have been confirmed at room temperature and at $184 \mathrm{~K}$. Space group Pmnn as well as $P n n 2$ is possible. In accordance with Wheatley (1957) the centrosymmetric space group Pmnn was chosen.

\section{Table 1. Unit-cell information at $184 \mathrm{~K}$}

Here and in the following tables, (least-squares) standard deviations are given in parentheses.

$\begin{array}{lcll}a & 9.325(4) \AA & Z & 2 \\ b & 5.850(2) & \text { Space group } P \text { mnn } \\ c & 3.733(1) & d_{c} & 1.306 \mathrm{~g} \mathrm{~cm}^{-1} \\ V & 203.6(2) \AA^{3} & \mu(\mathrm{Mo} K \alpha) & 0.80 \mathrm{~cm}^{-1}\end{array}$

\section{Data treatment}

During the measurements the three reference reflexions showed a consistent systematic decrease in intensity. Data were corrected for this effect by means of linear interpolation between two consecutive correction factors, calculated as an average from a set of reference reflexions. The same correction factor has been applied to the counting statistic variances.

Absorption correction for a spherical crystal $[\mu=$ $0.80 \mathrm{~cm}^{-1}$ : International Tables for X-ray Crystallography (1974)] by Gaussian quadrature (Margenau \& Murphy, 1957) was performed with the program $A C X R$ (Harkema, 1976). An approximate correction for the effect of the capillary tube was also included (Verschoor, 1967). Negligible corrections emerged from this cal- 
culation and the uncorrected data were used for further analysis.

Corrections for thermal diffuse scattering (TDS) were performed according to $I_{\mathrm{Bragg}}=I_{o} /(1+\alpha)$ [see, for example, Harada \& Sakata (1974) and Cochran (1969) for a short account of relevant theory]. $I_{\mathrm{Bragg}}$ represents the true Bragg intensity and $I_{o}$ the measured intensity. The TDS correction factor $\alpha$ has been calculated with the use of acoustic phonons only, and neglect of dispersion, primary beam divergence and mosaic spread. Proper care has been taken of elastic anisotropy and orientation of the crystal. The wavelength distribution is included approximately by calculating the correction factor for $K \alpha_{1}$ as well as $K \alpha_{2}$ radiation and using the intensity weighted average. Stevens's (1974) program, modified for use in connexion with the PW1100 diffractometer, was used. The computing time was reduced by a factor of about three by replacing the isometric grid numerical integration and the extrapolation procedure as used by Stevens by the Gaussian quadrature method (Margenau \& Murphy, 1957). The first-order TDS correction is probably a slight overcorrection (Helmholdt, 1975; Cochran, 1969). Therefore we did not include the effect of second-order TDS. The elastic constants used were those as determined by Reynolds (1973) at room temperature. Their temperature dependence has been neglected. [Compare the temperature dependence of the elastic constants of naphthalene (Kitaigorodsky, 1973).]

Each independent reflexion was measured approximately seven times (including those symmetry related). From the different measurements for each reflexion a weighted average and standard deviation were calculated. The weights used in averaging were chosen as inverse counting-statistic variances. The internal consistency index $R_{I}$, defined as $R_{I}=\sum(I-I) / \sum I$, where $I$ is the intensity of a reflexion and $I$ the corresponding weighted average, was $2.6 \%$ before TDS correction. After TDS correction the value decreased to $2 \cdot 5 \%$. Lorentz-polarization and monochromator corrections were performed in the usual way. Although a normal distribution in $I$ seems more justified, we assumed a normal distribution in $F$ for calculating $\sigma(F)$ from $\sigma(I)$. No numerical integration is required in this case (Rees, 1976). The total number of independent reflex- ions was 846 of which 605 had an intensity greater than twice their standard deviation.

\section{Refinements}

Full-matrix least-squares refinements have been carried out by a local modification of ORFLS (Busing, Martin $\&$ Levy, 1962). The function minimized was $\sum w\left(\left|F_{o}\right|-\right.$ $\left.k\left|F_{c}\right|\right)^{2}, k$ being the scale factor, $\left|F_{o}\right|$ the observed structure factor and $\left|F_{c}\right|$ the calculated structure factor. The weight $w$ for each reflexion was taken to be $w=\sigma^{-2}$, where $\sigma$ is the experimental standard deviation of $\left|F_{o}\right|$. The summation is over all independent reflexions (Hirshfeld \& Rabinovich, 1973).

In all cases atomic scattering factors were used as listed in International Tables for X-ray Crystallography (1974) $(\mathrm{C}, \mathrm{N})$ and for $\mathrm{H}$ as given by Stewart, Davidson \& Simpson (1965). In the refinements where the extinction correction has been performed, the procedure as given by Larson (1969) was used. This accounts for isotropic secondary extinction.

High-order (HO) refinements, with reflexions of $s>0.65 \AA^{-1}$ only, have been carried out. The $\mathrm{H}$ atom parameters (and when extinction correction was performed, also the extinction parameter) were kept fixed at their values resulting from the corresponding full-angle (FA) refinements. Relevant information about the refinements is given in Table 2. This table

Table 3. Positional $\left(\times 10^{5}\right)$ and thermal $\left(\times 10^{4}\right)$ parameters for the nitrogen atom

The anisotropic temperature factor used was $\exp \left[-2 \pi^{2}\left(h^{2} a^{* 2} U_{11}+k^{2} b^{* 2} U_{22}+l^{2} c^{* 2} U_{33}\right.\right.$ $\left.\left.+2 h k a^{*} b^{*} U_{12}+2 h l a^{*} c^{*} U_{13}+2 k l b^{*} c^{*} U_{23}\right)\right]$.

The different models are given in Table 2. $Y / b, Z / c, U_{12}$ and $U_{13}$ vanish as a consequence of symmetry of the special positions (e) of space group Pmnn (International Tables for X-ray Crystallography, 1952).

$\begin{array}{cccccc}\text { Model } & X / a & U_{11} & U_{22} & U_{33} & U_{23} \\ 1 & 14996(8) & 208(2) & 327(3) & 403(4) & 65(3) \\ 2 & 14996(8) & 207(2) & 326(3) & 402(4) & 65(3) \\ 3 & 14986(8) & 186(3) & 295(3) & 411(5) & 61(3) \\ 4 & 14986(8) & 186(3) & 295(3) & 412(5) & 61(3) \\ 5 & 14995(8) & 237(2) & 357(3) & 434(4) & 67(3) \\ 6 & 14994(8) & 238(2) & 358(3) & 435(4) & 68(3) \\ 7 & 14987(8) & 225(3) & 335(3) & 452(5) & 61(3) \\ 8 & 14987(8) & 225(3) & 335(3) & 452(5) & 61(3)\end{array}$

Table 2. Refinement information

(No) $\mathrm{X}=$ (no) $\mathrm{X}$ correction performed, where $\mathrm{X}$ stands for either TDS or extinction (Ext.); FA=full-angle refinement; HO=highorder refinement; $R=\sum \Delta F / \sum F_{o} ; R_{w}=\left(\sum w \Delta F^{2} / \sum w F_{o}^{2}\right)^{1 / 2} ; S=\left[\sum w \Delta F^{2} /(n-m)\right]^{1 / 2} ; \Delta F=\left|F_{o}-F_{c}\right| ; w=1 / \sigma^{2}\left(F_{o}\right) ; n=$ number of reflexions; $m=$ number of parameters.

$\begin{array}{cr}\text { Model } & \\ 1 & \text { No TDS } \\ 2 & \text { No TDS } \\ 3 & \text { No TDS } \\ 4 & \text { No TDS } \\ 5 & \text { TDS } \\ 6 & \text { TDS } \\ 7 & \text { TDS } \\ 8 & \text { TDS }\end{array}$

$\begin{array}{cc}\text { No } & \text { Ext. } \\ & \text { Ext. } \\ \text { No } & \text { Ext. } \\ & \text { Ext. } \\ \text { No } & \text { Ext. } \\ & \text { Ext. } \\ \text { No } & \text { Ext. } \\ & \text { Ext. }\end{array}$

$R(\%)$
$7 \cdot 7$
$7 \cdot 7$
$12 \cdot 0$
$12 \cdot 0$
$7 \cdot 1$
$7 \cdot 1$
$11 \cdot 6$
$11 \cdot 6$

$\begin{array}{cc}R_{w}(\%) & S \\ 5 \cdot 0 & 2 \cdot 85 \\ 5.0 & 2 \cdot 84 \\ 5 \cdot 8 & 1.68 \\ 5 \cdot 8 & 1.68 \\ 4.7 & 2 \cdot 63 \\ 4.7 & 2.63 \\ 6.0 & 1.68 \\ 6.0 & 1.68\end{array}$

Scale

40.65 (14)

$40 \cdot 54$ (15)

$38.05(42)$

$38 \cdot 28(51)$

$41.90(14)$

$41 \cdot 94(15)$

40.97 (46)

40.97 (46) 
Table 4. Positional $\left(\times 10^{5}\right)$ and thermal $\left(\times 10^{4}\right)$ parameters for the carbon atom

See Table 3 for the legend to this table.

\begin{tabular}{|c|c|c|c|c|c|c|c|c|c|}
\hline Model & $X / a$ & $Y / b$ & $Z / c$ & $U_{11}$ & $U_{22}$ & $U_{33}$ & $U_{12}$ & $U_{13}$ & $U_{23}$ \\
\hline 1 & $7439(7)$ & $17739(10)$ & $12084(18)$ & $278(2)$ & $265(2)$ & $346(3)$ & -39 (2) & $-33(2)$ & 30 (2) \\
\hline 2 & $7440(7)$ & $17739(10)$ & $12085(18)$ & 277 (2) & 264 (2) & 345 (3) & $-38(2)$ & $-33(2)$ & $30(2)$ \\
\hline 3 & $7437(7)$ & $17774(10)$ & $12189(24)$ & $253(3)$ & $245(3)$ & 341 (4) & $-30(2)$ & $-28(2)$ & $19(2)$ \\
\hline 4 & 7437 (7) & $17774(10)$ & $12189(24)$ & $253(3)$ & 245 (3) & 341 (4) & $-30(2)$ & $-28(2)$ & $19(2)$ \\
\hline 5 & $7442(7)$ & $17735(9)$ & $12085(16)$ & $307(2)$ & $295(2)$ & $374(3)$ & $-39(2)$ & $-32(2)$ & $30(2)$ \\
\hline 6 & $7442(7)$ & $17735(9)$ & $12085(17)$ & $308(2)$ & $295(2)$ & $375(3)$ & $-39(2)$ & $-33(2)$ & $30(2)$ \\
\hline 7 & 7440 (7) & $17774(10)$ & $12193(24)$ & $292(3)$ & $285(3)$ & 381 (4) & $-30(2)$ & $-28(2)$ & 19 (2) \\
\hline 8 & $7440(7)$ & $17774(10)$ & $12193(24)$ & 292 (3) & $285(3)$ & 381 (4) & $-30(2)$ & $-28(2)$ & 19 (2) \\
\hline
\end{tabular}

Table 5. Positional and thermal parameters of the hydrogen atom

Positional and thermal parameters are $\times 10^{3}$. The isotropic temperature factor used was $\exp \left(-8 \pi^{2} U \sin ^{2} \theta / \lambda^{2}\right)$. The different models are given in Table 2.

$\begin{array}{ccccc}\text { Model } & X / a & Y / b & Z / c & U \\ 1,3 & 127(1) & 304(2) & 189(2) & 41(3) \\ 2,4 & 127(1) & 304(2) & 189(2) & 41(2) \\ 5,7 & 128(1) & 305(2) & 194(2) & 43(2) \\ 6,8 & 128(1) & 305(2) & 194(2) & 43(2)\end{array}$

also enumerates the different models used. It may be useful to mention that $R$ values drop several percent if only significant reflexions $\left[\left|F_{o}\right|>2 \sigma\left(\left|F_{o}\right|\right)\right]$ are included. $R_{w}$ values are virtually unchanged and $S$ values increase.

Final positional and thermal parameters are given in Tables 3, 4 and 5. Bond distances and angles derived from them are in Table $6 .^{*}$

* A list of structure factors has been deposited with the British Library Lending Division as Supplementary Publication No. SUP 31954 (16 pp., 1 microfiche). Copies may be obtained through The Executive Secretary, International Union of Crystallography, 13 White Friars, Chester CHI 1NZ, England.

\section{Thermal parameters}

The root-mean-square displacements (r.m.s.d.'s) on principal axes of the $\mathrm{C}$ and $\mathrm{N}$ atoms (and the isotropic r.m.s.d. of the $\mathrm{H}$ atom) are given in Table 7.

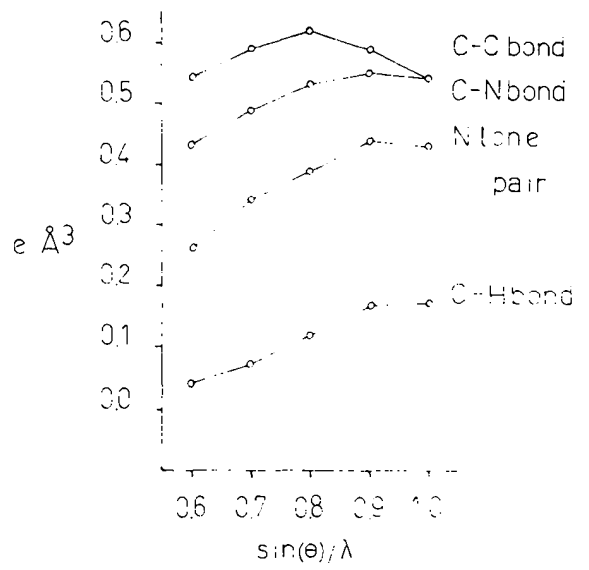

Fig. 1. Convergence of the value of $\Delta \varrho$ in bond and lone-pair regions as a function of the $\sin \theta / \lambda$ cut-off value. High-order parameters derived from the data not corrected for TDS were used.

\section{Table 6. Bond distances $(\AA)$ and angles $\left({ }^{\circ}\right)$}

The different models are given in Table 2, except model 9 which refers to the bond lengths and angles corrected for thermal motion. (The effect of estimated error in coordinates due to librational corrections is included in the standard deviations.)

\begin{tabular}{|c|c|c|c|c|c|c|c|}
\hline Model & $\mathrm{C}-\mathrm{N}$ & $\mathrm{C}-\mathrm{C}$ & C-H & $\mathrm{C}-\mathrm{C}-\mathrm{N}$ & $\mathrm{C}-\mathrm{N}-\mathrm{C}$ & $\mathrm{C}-\mathrm{C}-\mathrm{H}$ & $\mathrm{N}-\mathrm{C}-\mathrm{H}$ \\
\hline 1,2 & $1 \cdot 3330(7)$ & $1 \cdot 3875(9)$ & $0.92(1)$ & $121 \cdot 91(7)$ & $116 \cdot 18(7)$ & $122.0(1.2)$ & $116 \cdot 0(0 \cdot 8)$ \\
\hline 3,4 & $1.3355(8)$ & $1 \cdot 3871(9)$ & 0.92 (1) & $121 \cdot 81(8)$ & $116.39(7)$ & $122 \cdot 1(1 \cdot 2)$ & $115.9(0.8)$ \\
\hline 5,6 & $1.3327(7)$ & $1 \cdot 3879(9)$ & 0.94 (1) & $121.90(7)$ & $116.19(7)$ & $122.0(1.0)$ & $116 \cdot 1(0 \cdot 7)$ \\
\hline 7,8 & $1.3355(8)$ & $1.3875(10)$ & $0.94(1)$ & $121 \cdot 80(8)$ & $116 \cdot 40(7)$ & $122 \cdot 1(1 \cdot 1)$ & $116.0(0.7)$ \\
\hline 9 & $1.3392(18)$ & $1 \cdot 3931(26)$ & $1.08(1)^{*}$ & $121 \cdot 84(16)$ & $116 \cdot 31(14)$ & $122 \cdot 2(2 \cdot 1)$ & $115.9(1.4)$ \\
\hline $\begin{array}{l}\text { Wheatley, } \\
\text { uncorrected }\end{array}$ & $1 \cdot 314(3)$ & 1.358 & 1.05 & $122 \cdot 4(1 \cdot 0)$ & $115 \cdot 1(1 \cdot 0)$ & $120 \cdot 3(1 \cdot 0)$ & $116.9(1.0)$ \\
\hline Wheatley, & 1.334 & $1.378(15)$ & .00 & (2)- & $1+10 \times(1+0)$ & & \\
\hline
\end{tabular}

* This distance is calculated from the $\mathrm{C}-\mathrm{H} / \mathrm{C}-\mathrm{C}$ bond-length ratio as determined by NMR methods.

Table 7. Root-mean-square displacements $(\AA)$ along the principal axes

Estimated standard deviations: $10^{-3} \AA$ for $\mathrm{C}$ and $\mathrm{N}, 8 \times 10^{-3} \AA$ for $\mathrm{H}$.

$\begin{array}{cccccccc}\text { Model } & U_{1}(\mathrm{~N}) & U_{2}(\mathrm{~N}) & U_{3}(\mathrm{~N}) & U_{1}(\mathrm{C}) & U_{2}(\mathrm{C}) & U_{3}(\mathrm{C}) & U(\mathrm{H}) \\ 1,2 & 0 \cdot 1440 & 0 \cdot 1699 & 0 \cdot 2095 & 0 \cdot 1669 & 0 \cdot 1521 & 0 \cdot 1930 & 0 \cdot 2025 \\ 3,4 & 0.1364 & 0 \cdot 1640 & 0.2091 & 0 \cdot 1626 & 0 \cdot 1477 & 0 \cdot 1887 & 0 \cdot 2025 \\ 5,6 & 0 \cdot 1541 & 0.1784 & 0.2176 & 0 \cdot 1762 & 0 \cdot 1616 & 0 \cdot 2012 & 0 \cdot 2074 \\ 7.8 & 0.1500 & 0.1758 & 0.2186 & 0.1744 & 0 \cdot 1607 & 0 \cdot 1989 & 0 \cdot 2074\end{array}$


Extinction has a negligible influence on the thermal parameters (Tables 3,4 and 5) and hence on the r.m.s.d.'s (Table 7).

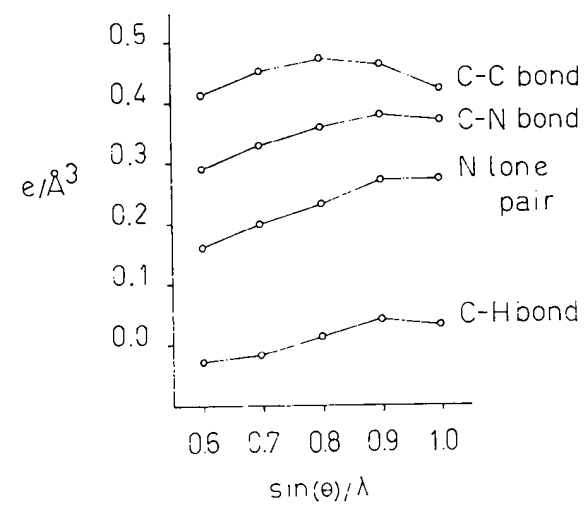

Fig. 2. Convergence of the value of $\Delta \varrho$ in bond and lone-pair regions as a function of the $\sin \theta / \lambda$ cut-off value. High-order parameters derived from the data corrected for TDS were used.
With HO parameters instead of FA parameters, the r.m.s.d's decrease on average $0.005 \AA$. However, the use of data corrected for TDS results in r.m.s.d.'s increased by about $0 \cdot 010 \AA$. Thus the combined effect is to increase the r.m.s.d.'s by ca $0.005 \AA$, approximately five times the standard deviation. This effect has been noticed before (Helmholdt, 1975).

The pyrazine molecule occupies a centre of symmetry in the crystal lattice. Hence the rigid-body motion can be described in terms of the $\mathbf{T}$ and $\mathbf{L}$ tensors (Schomaker $\&$ Trueblood, 1968). Since the thermal parameters of the $\mathrm{C}$ and $\mathrm{N}$ atoms do not uniquely determine the $\mathrm{T}$ and $\mathrm{L}$ tensors, certain assumptions have to be made. Wheatley (1957) assumed that half of the thermal motion component normal to the molecular plane is due to libration. By taking into account the $\mathrm{H}$ thermal parameter no assumptions have to be made, but the results will not be very accurate. In Table 8 the $\mathbf{T}$ and $\mathbf{L}$ tensors derived from model 7 (see Table 2 for nomenclature) are given. Other models yield similar results.

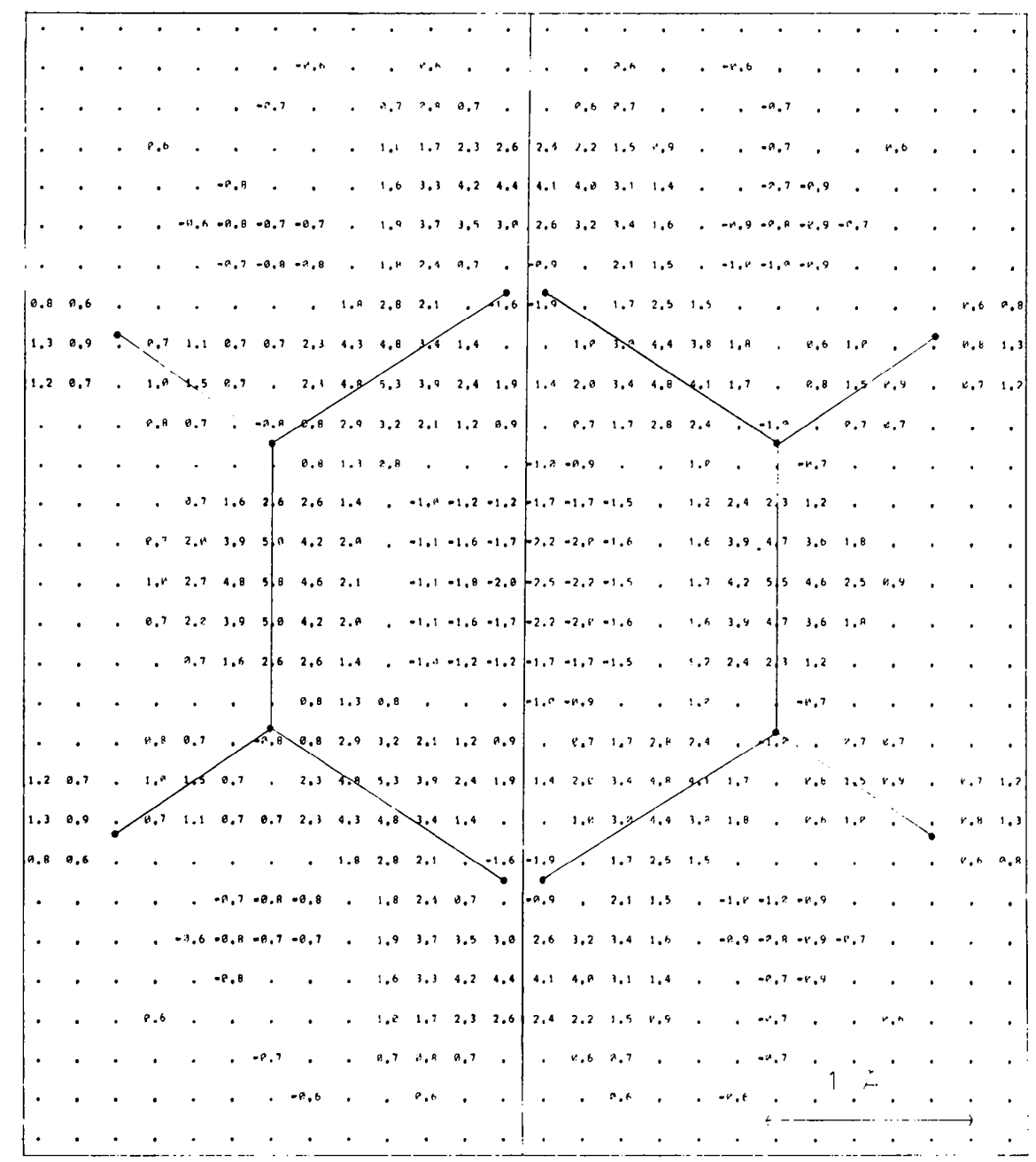

Fig. 3. Difference-Fourier map in the plane of the molecule calculated from data not corrected for TDS. Left half: not corrected for extinction; right half: corrected for extinction. Units: $0 \cdot 1 \mathrm{e} \AA^{-3}$. 
Table 8. $\mathbf{T}$ and $\mathbf{L}$ tensors relative to the crystal axes and their principle values

\begin{tabular}{|c|c|c|c|}
\hline $\mathbf{T}\left(10^{-2} \AA^{2}\right)$ & {$[2 \cdot 69(17)$} & $\begin{array}{l}0 \cdot 0 \\
3 \cdot 10(15)\end{array}$ & $\begin{array}{l}0.0 \\
0.36(18) \\
3 \cdot 40(29)\end{array}$ \\
\hline Principle values & $2 \cdot 69$ & $3 \cdot 64$ & $2 \cdot 87$ \\
\hline $\mathbf{L}\left(\right.$ deg. $\left.^{2}\right)$ & {$[4 \cdot 4(2 \cdot 9)$} & $\begin{array}{l}0.0 \\
15.0(6.4)\end{array}$ & $\begin{array}{l}0.0 \\
1.6(3.3) \\
11.4(2.5)\end{array}$ \\
\hline Principle values & $4 \cdot 4$ & $15 \cdot 6$ & $10 \cdot 8$ \\
\hline
\end{tabular}

\section{Bond lengths and angles}

From Tables 3, 4 and 5 it can be seen that extinction correction has no influence on the positional parameters. Therefore the resulting bond distances and angles (Table 6) are also unaffected.

The influence of TDS on the positions of the atoms is also insignificant. This result was more or less expected in view of the theoretical analysis (Harada \&
Sakata, 1974) and model calculations (Helmholdt, 1975) performed earlier.

On comparing FA and $\mathrm{HO}$ parameters the maximum difference between corresponding bond distances and angles is found to be about three times the standard deviation ( $\mathrm{C}-\mathrm{N}$ bond and $\mathrm{C}-\mathrm{N}-\mathrm{C}$ angle). Using $\mathrm{HO}$ data instead of FA data affects mainly the position of the $\mathrm{C}$ atom (shift out of the ring perpendicular to a line connecting the two $\mathrm{N}$ atoms).

The rigid-body motion described in the previous paragraph serves as a basis to estimate the corrections on the molecular geometry due to thermal motion (Schomaker \& Trueblood, 1968). The corrections are presented only for model 7. In Table 6 the result is given as model 9 (except for the $\mathrm{C}-\mathrm{H}$ distance which is discussed below). Corrections calculated from other models yield similar results. From Table 6 it can be seen that the corrections on bond distances are small. Corrections on bond angles can safely be neglected.

By means of NMR methods (Diehl, Bösiger, Tracy \& Ader, 1976) the ratio of the meta-C-C to the ortho-

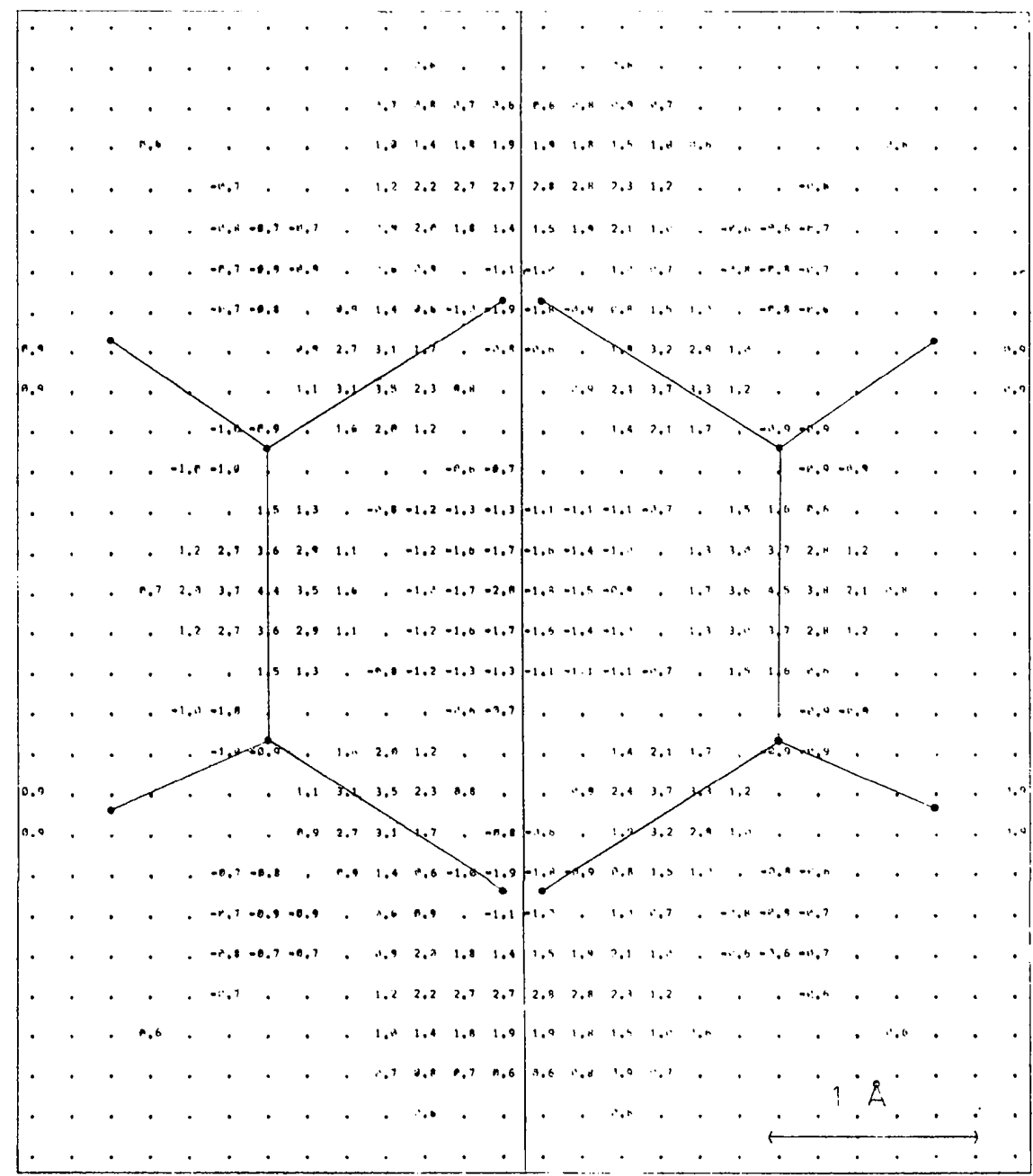

Fig. 4. Difference-Fourier map in the plane of the molecule calculated from data corrected for TDS. Left half: not corrected for extinction; right half: corrected for extinction. Units: $0 \cdot 1$ e $\AA^{-3}$. 
C-C distance has been determined as $1 \cdot 619 \pm 0.009$. This value is virtually the same as determined in this work: $1.633 \pm 0.001$ (based on data corrected for thermal motion).

Using the ratio of the $\mathrm{C}-\mathrm{H}$ and ortho- $\mathrm{C}-\mathrm{C}$ distances [0.778 \pm 0.007 : Diehl et al. (1976)] we calculate the $\mathrm{C}-\mathrm{H}$ bond length as $1.08 \pm 0.01 \AA$. This is the value of the $\mathrm{C}-\mathrm{H}$ bond length as mentioned for model 9 in Table 6. This model represents the best estimate of the geometrical structure of pyrazine.

\section{Charge distribution}

Positional and thermal parameters, which should be reasonably free of bias due to bonding effects (compare Stevens \& Hope, 1975), having been determined, three more questions concerning the charge distribution remain:

First, the scale factor for calculating the differenceFourier map, $\Delta \varrho$. Model calculations (Ruysink \& Vos,
1974) indicate that the HO scale factor would be the most appropriate for calculating $\Delta \varrho$. However, Fourier maps calculated with this scale factor do show positive values in nuclear regions, indicating that the scale factor obtained may not be the correct one. Therefore one least-squares cycle refining only the scale factor (for the LO data) was carried out before calculating $\Delta \varrho$.

Second, the optimum $s$ value for cutting off the Fourier series when calculating $\Delta \varrho$. A plot of the value of $\Delta \varrho$ at several points in the molecule as a function of the cut-off value is given in Fig. 1. The data set not corrected for TDS was used. The same characteristics are to be seen in a plot (Fig. 2) constructed from the corrected data. It is clear that Fourier terms with $s>0.65 \AA^{-1}$ should be included. From the plot we conclude that $s=0.85 \AA^{-1}$ is a reasonable value. The corresponding resolving power, $0 \cdot 715 \lambda /\left(2 \sin \theta_{\max }\right)$, is $0.42 \AA$ [see Rees (1976) for discussion].

Finally, the standard deviation in $\Delta \varrho$. With the average standard deviation estimated as $\sigma(\Delta \varrho)=1 / V\left[\sum \sigma^{2}(F)\right]^{1 / 2}$,

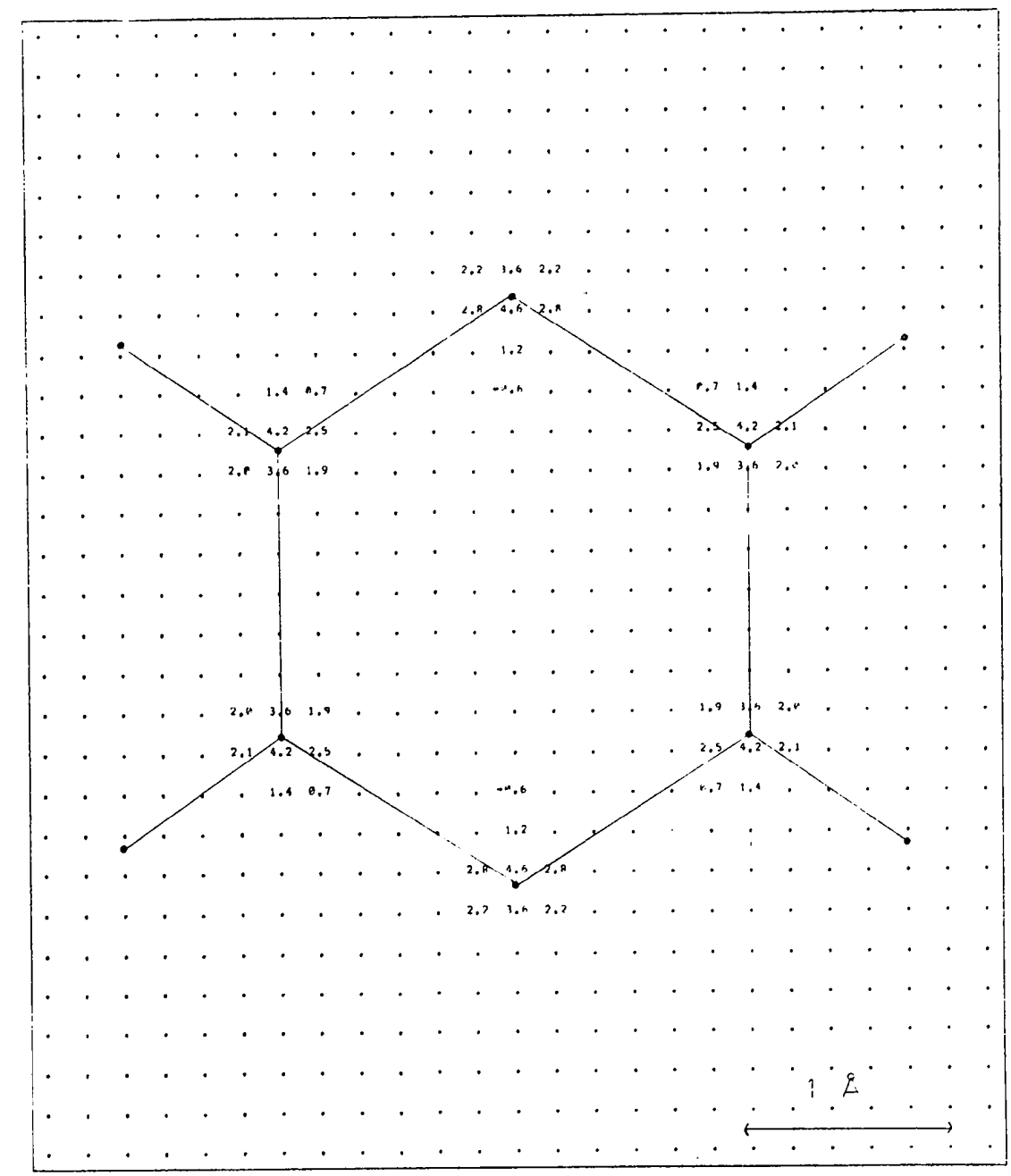

Fig. 5. Fourier map of the TDS intensity. Units: 1.0 e $\AA^{-3}$. 
a value of $0.035 \mathrm{e} \AA^{-3}$ was calculated. Examination of values of $\Delta \varrho$ at points far removed from the moleculcs shows a variation of roughly twice this value.

With the HO parameters sets, difference-Fourier maps were calculated in the plane of the molecule. All calculations were performed by the program SPFT (van de Waal, 1975). Reflexions with $s \leq 0.85 \AA^{-1}$ were used. Fig. 3 shows $\Delta \varrho$ calculated from data not corrected for TDS. The left and right halves respectively show the map not corrected for extinction and the corrected map. In Fig. 4 the corresponding maps calculated from the data corrected for TDS are given. It is clear that extinction has no significant influence.

On the other hand, on comparing Figs. 3 and 4 it is also clear that the changes after correction for TDS are far from negligible. Bond as well as lone-pair densities decrease by about 0.15 e $\AA^{-3}$. The effect found is roughly five times larger than predicted by the model calculations of Helmholdt (1975).

Finally, in Fig. 5, a Fourier synthesis of the difference between corrected and uncorrected data (i.e. the TDS intensity) is presented. This transform is concentrated mainly in the nuclear regions. A picture showing the same feature was also given by Helmholdt (1975). In nuclear regions the value of $\Delta \varrho$ is rather uncertain. Thus the main reason for correcting for TDS is its influence on thermal parameters and, through them, on the calculated difference density. This influence is also present if thermal parameters are determined by diffraction techniques using ultrasonic neutrons (Willis \& Pryor, 1975). Finally it should be remarked that the calculation of the TDS correction is still approximate [see for example, Cochran (1969) for discussion]. Furthermore, because of the rather small elastic constants of pyrazine, the influence of TDS may be more important in this case than in crystals normally used in electron density studies.

Many thanks are due to Dr E. D. Stevens for supplying a listing of his program $T D S 2$ and to Mr R.A.P. Mulder for his help in modifying it.

\section{References}

Busing, W. R., Martin, K. O. \& Levy, H. A. (1962). ORFLS. Oak Ridge National Laboratory Report ORNL-TM-305.

Cochran, W. (1969). Acta Cryst. A 25, 95-101.

Diehl, P., Bösiger, H., Tracy, A. S. \& Ader, R. (1976). Org. Magn. Resonance, 8, 17-18.

Harada, J. \& Sakata, M. (1974). Acta Cryst. A30, 77-82.

HARKema, S. (1976). $A C X R$, Absorption correction program for use in connexion with the PW1100 diffractometer.

Helmholdt, R. B. (1975). Thesis (in Dutch). State Univ. of Groningen, Groningen, The Netherlands. [See also Acta Cryst. (1975), A31, S226.]

Hirshfeld, F. L. \& Rabinovich, D. (1973). Acta Cryst. A 29, 510-513.

International Tables for X-ray Crystallography (1952). Vol. I, p. 146. Birmingham: Kynoch Press.

International Tables for X-ray Crystallography (1974). Vol. IV. Birmingham: Kynoch Press.

Kitaigorodsky, A. I. (1973). Molecular Crystals and Molecules, p. 366. New York: Academic Press.

Larson, A. C. (1969). Crystallographic Computing, edited by F. R. AHMED, pp. 291-294. Copenhagen: Munksgaard.

Margenau, H. \& Murphy, G. M. (1957). The Mathematics of Physics and Chemistry, pp. 479-481. Princeton: Van Nostrand.

ReES, B. (1976). Acta Cryst. A32, 483-488.

Reynolds, P. A. (1973). J. Chem. Phys. 59, 2777-2786.

Ruysink, A. F. J. \& Vos, A. (1974). Acta Cryst. A30, 503-506.

Schomaker, V. \& Trueblood, K. N. (1968). Acta Cryst. A 25, 63-76.

Stevens, E. D. (1974). Acta Cryst. A 30, 184-189.

Stevens, E. D. \& Hope, H. (1975). Acta Cryst.A 31, 494-498.

Stewart, R. F., Davidson, E. R. \& Simpson, W. T. (1965). J. Chem. Phys. 42, 3175-3187.

Verschoor, G. C. (1967). Thesis (in Dutch), pp. 51-52. State Univ. of Groningen, Groningen, The Netherlands.

WAAL, B. W. VAN DE (1975). SPFT. Slant Plane Fourier Transform Program. Progress Report No. 14. Chemical Physics Laboratory, Twente Univ. of Technology, Enschede, The Netherlands.

Wheatley, P. J. (1957). Acta Cryst. 10, 182-187.

Willis, B. T. M. \& PRYOR, A. W. (1975). Thermal Vibrations in Crystallography, pp. 239-240. Cambridge Univ. Press. 


\title{
Crystal and Molecular Structure of the Red Form of Bis(N,N-diethylethylenediamine)copper(II) Perchlorate
}

\author{
By Marta M. Andino, Juan D. Curet* and Mariel M. Muir \\ Department of Chemistry, University of Puerto Rico, Río Piedras, P.R. 00931, U.S.A. \\ AND ROBERT C. RYAN \\ Department of Chemistry, University of Wisconsin, Madison, Wisconsin 53705, U.S.A.
}

(Received 23 January 1976; accepted 14 May 1976)

\begin{abstract}
The investigation of the structure of red thermochromic bis( $N, N$-diethylethylenediamine)copper(II) perchlorate is the first of two studies for explaining its $46^{\circ} \mathrm{C}$ transition to a violet form. The crystals are triclinic at room temperature, space group $C \bar{T}, a=17.868$ (1), $b=8.104$ (1), $c=10.039$ (1) $\AA, \alpha=$ $90.40(1), \beta=131.63(1), \gamma=90.45(2)^{\circ}, d=1.511 \mathrm{~g} \mathrm{~cm}^{-3}, V$ (unit cell) $=1086 \AA^{3}$, and $Z=2$. The structure was determined by the heavy-atom technique. Intensities were obtained from $\theta-29$ scans with a fourcircle automatic diffractometer using graphite-monochromatized Mo $K \alpha$ radiation. The 1306 reflections were refined to $R=0 \cdot 040$ by full-matrix least squares. The crystal is composed of

$\mathrm{Cu}\left(\mathrm{H}_{2} \mathrm{NCH}_{2} \mathrm{CH}_{2} \mathrm{NEt}_{2}\right)_{2}^{2+}$ cations and $\mathrm{ClO}_{4}^{-}$anions. The $\mathrm{Cu}^{11}$ is coordinated to two molecules of $N, N$-diethylethylenediamine through the $\mathrm{N}$ atoms resulting in a square-planar $\mathrm{CuN}_{4}$ stoichiometry. The five-membered $\mathrm{Cu}$-diamine rings adopt a symmetrical-skew conformation with the ring $\mathrm{C}$ atoms lying 0.322 and $0.329 \AA$ above and below the $\mathrm{CuN}_{4}$ plane. The bond distances are $\mathrm{Cu}-\mathrm{N}$ (primary) 2.003 (4), $\mathrm{Cu}-\mathrm{N}$ (tertiary) 2.060 (4), N-C (mean) $1.485, \mathrm{C}-\mathrm{C}$ (mean) $1.497 \AA$. The $\mathrm{N}(1)-\mathrm{Cu}-\mathrm{N}(2)$ angle is $84.4(2)^{\circ}$. The $\mathrm{ClO}_{4}^{-}$anion is tetrahedral, $\mathrm{Cl}-\mathrm{O}$ distance (mean) $1.405 \AA$ and $\mathrm{O}-\mathrm{Cl}-\mathrm{O}$ angle $109 \cdot 4^{\circ}$. The oxygens, $\mathrm{O}(3)$, nearest to $\mathrm{Cu}$ are 3.649 (5) $\AA$ away. The vector $\mathrm{O}(3)-\mathrm{Cu}-\mathrm{O}\left(3^{\prime}\right)$ intersects the $\mathrm{CuN}_{4}$ plane at $59 \cdot 5^{\circ}$.
\end{abstract}

\section{Introduction}

The thermochromic substance

$\mathrm{Cu}\left(\mathrm{Et}_{2} \mathrm{NCH}_{2} \mathrm{CH}_{2} \mathrm{NH}_{2}\right)_{2}\left(\mathrm{ClO}_{4}\right)_{2}$, hereafter called compound $\mathrm{I}$, changes color from brick red to violet near $46^{\circ} \mathrm{C}$. The vibrational, electronic and magnetic properties of this compound have been extensively studied at various temperatures. The crystal structures of several related bis(ethylenediamine)-copper complexes have been determined (Pajunen, 1967, 1969; Nasanen, Virtamo \& Myllymaki, 1966) together with their electronic and far-infrared spectra (Lever \& Mantovani, 1971). Two extreme structures were recognized: a square-planar complex with an in-plane $\mathrm{CuN}_{4}$ stoichiometry and with the anionic $\mathrm{X}$ groups beyond bonding distance, and a tetragonally distorted octahedral complex with axially coordinating $\mathrm{X}$ groups. The position of the $d-d$ absorption bands has been taken as an indication of the degree of tetragonal distortion. A correlation was made between these bands and the highest energy $\mathrm{Cu}-\mathrm{N}$ stretching mode. It was postulated that an increase in the in-plane field strength due to a tightening up of the in-plane bond when the axial interaction weakens has an effect on the in-plane $\mathrm{Cu}-\mathrm{N}$ stretching frequency. Both the electronic transition and the metal-ligand stretching frequencies increase as the structure becomes more tetragonally distorted. The decrease in the electronic band maximum of compound I from 20700 to $19305 \mathrm{~cm}^{-1}$ and the de-

\footnotetext{
* Author to whom correspondence should be addressed.
}

crease in the $\mathrm{Cu}-\mathrm{N}$ stretching frequency from 405 to $403 \mathrm{~cm}^{-1}$ as the temperature increases from 22 to $78^{\circ} \mathrm{C}$ was taken as the result of a decrease in the tetragonality of the complex, which explains the changes that accompany the transition observed at $46^{\circ} \mathrm{C}$ (Lever, Mantovani \& Donini, 1971). It was also seen that the weak band appearing at $933 \mathrm{~cm}^{-1}$ and which was assigned to a symmetric stretching vibration $v_{1}$ allowed in a $C_{3 v}$ symmetry intensifies by about $40 \%$ at $78^{\circ} \mathrm{C}$. This was assumed to be an increased ion perturbation arising through coordination of one $\mathrm{O}$ to $\mathrm{Cu}^{2+}$. The variation in the frequency of the $d-d$ band with temperature has also been observed to correlate well with the transition temperature observed by differential scanning calorimetry (Fabbrizzi, Micheloni \& Paoletti, 1974; Andino, 1974).

ESR studies of compound I in the polycrystalline state at $-196,22$ and $80^{\circ} \mathrm{C}$, and in the magneticallydilute state in $\mathrm{Ni}\left(a s-\mathrm{Et}_{2} \mathrm{en}\right)_{2}\left(\mathrm{ClO}_{4}\right)_{2}$ powder at -196 , 22 and $120^{\circ} \mathrm{C}$ were performed by Yokoi, Sai \& Isobe (1969). Assuming compound I to be trans-square coplanar with the two perchlorate anions located at the axial positions and knowing the relations between the ESR data and the covalency parameters, it was concluded that the difference in structure of compound I in the magnetically-dilute state at the three temperatures lies mainly in the axial coordination and that the axial ligand field is strengthened as the temperature increases. The behavior of compound $\mathrm{I}$ in the polycrystalline state at 22 and $80^{\circ} \mathrm{C}$ was different, which led them to believe that this phase transition was of a 